\title{
The Ground Settlement and the Existing Pipeline Response Induced by the Nonsynchronous Construction of a Twin-Tunnel
}

\author{
Shicheng Sun $\mathbb{D},,^{1,2}$ Chuanxin Rong $\mathbb{D}^{1,2}$ Houliang Wang $\mathbb{D}^{1},{ }^{3}$ Linzhao Cui $\mathbb{D}^{\mathrm{D}},{ }^{3}$ \\ and Xin Shi $\mathbb{D i D}^{2}$ \\ ${ }^{1}$ State Key Laboratory of Mining Response and Disaster Prevention and Control in Deep Coal Mine, \\ Anhui University of Science and Technology, Huainan 232001, China \\ ${ }^{2}$ School of Civil Engineering and Architecture, Anhui University of Science and Technology, Huainan 232001, China \\ ${ }^{3}$ Anhui Water Resources Development Co., Ltd., Bengbu 233000, China \\ Correspondence should be addressed to Chuanxin Rong; rongcx@ustc.edu
}

Received 4 September 2020; Revised 4 March 2021; Accepted 17 March 2021; Published 31 March 2021

Academic Editor: Wen-Chieh Cheng

Copyright $(2021$ Shicheng Sun et al. This is an open access article distributed under the Creative Commons Attribution License, which permits unrestricted use, distribution, and reproduction in any medium, provided the original work is properly cited.

\begin{abstract}
Shielding tunnel construction always has negative impacts on the surrounding buildings. Because of repeated disturbances caused by the construction, more attention should be paid to the impacts of the nonsynchronous construction of a twin-tunnel. In this research, a three-dimensional model was established to simulate the construction process of a twin-tunnel in a section of the Hefei No. 4 metro line, and the calculation results were validated with the measured settlement data. Based on the model, the ground settlement and the existing pipeline responses were studied in detail. The results showed that, after the first tunnel (FT) construction, the settlement curves conformed to a Gaussian distribution. Additionally, after the second tunnel (ST) construction, the final settlement curves were no longer completely symmetrical. The influences of the twin-tunnel space and the pipeline-soil relative stiffness on the settlements were further studied. The results showed that the final settlement curves of the ground surface and the pipeline were mainly $\mathrm{W}$-shaped, U-shaped, and V-shaped. As the twin-tunnel space increased and the pipeline-soil relative stiffness decreased, the settlement curve gradually changed from $\mathrm{V}$-shaped to $\mathrm{W}$-shaped. $C$ was defined as the ratio of two maximum settlements in the $\mathrm{W}$-shaped settlement curve. As the space increased, $C$ started to decrease from 1 and then increased to 1 .
\end{abstract}

\section{Introduction}

The construction of a tunnel is a complex engineering problem involving many aspects. Taking into account the uncertainty of the geological lithology and the complexity of the construction environment, more consideration should be given to the soil-structure interaction during tunnel construction, and efforts should be made to reduce the adverse impacts of tunnel construction [1-3]. In particular, in urban areas, because of the interaction between the soil and the structure, the disturbance caused by shielding construction may reduce the safety of roads and pipelines $[4,5]$. When a tunnel crosses pipelines at close range, it can easily cause ground settlement and deformation or even the destruction of the pipelines [6,7], which will seriously affect the production and life of the surrounding residents and result in negative economic and social impacts. Considering this situation, it is necessary to conduct an in-depth study of the settlement behaviors caused by twin-tunnel construction.

Many scholars have achieved research results related to the influence mechanisms of tunnel construction and the prediction method of settlements. The Peck formula is the most widely used by engineers and researchers. Based on this, many scholars have conducted in-depth research studies [9-11]. The analytical method has been used to obtain the settlements of the ground and pipelines through the pipeline-soil interaction. Attewell et al. [12] and Wei et al. [13-15] established an analytical solution for soil deformation. Based on the Winkler foundation model, Huang et al. [16] and Shi et al. $[17,18]$ considered the interaction of a tunnel-soil-pipeline. A series of finite element simulations 
were also used for relevant research studies. Wang et al. [19] and Shi et al. [20, 21] analyzed the sensitivity of each parameter to the settlement of the ground and a pipeline based on numerical simulation. In addition, the effects of different pipeline orientations on tunneling were studied via a centrifugal test. Ma et al. [22] carried out a three-dimensional centrifugal model test and a numerical simulation to study the influence of double-stack tunnel construction on existing pipelines with different construction sequences. Previous research has made predictions, primarily about the final settlement of the ground and a pipeline after tunnel construction, but little attention has been paid to the development of the settlement with the second construction disturbance.

In this research, the settlements of the ground surface and the response of a pipeline during nonsynchronous twintunnel construction were studied. The in-depth analysis of the characteristics of the settlement development was introduced during the FT and ST construction. At the same time, to determine the final settlement characteristics of the ground surface and pipeline, we further studied the influences of the pipeline-soil relative stiffness and the twintunnel space on the final settlements.

\section{Analysis of the Ground Settlements and the Pipeline Response}

The phenomenon of ground movement and the pipeline deformation caused by tunnel shielding is a three-dimensional problem that can be explained by the interaction of a tunnel-soil-pipeline [21]. According to Shi et al. [20], it can be known that, from the vertical direction, this phenomenon mainly includes the stress relief caused by the excavation of the construction plane, the pressure imbalance caused by the grouting, and the consolidation settlement caused by the change of the water level. During the construction process, the formation loss is transmitted upward to cause the deformation of the surface and buried pipelines. In this process, the pressure of the overlying soil of the pipeline and the emptying of the underlying soil cause the deformation and overall displacement of the pipeline [23]. At the same time, the existence of the pipeline as a "beam" in the soil also reduces the settlement of the ground surface. The interaction is coordinated, and eventually the interaction will be stabilized.

Generally speaking, the impact of a tunnel vertically undercrossing the ground and a pipeline is the largest [24]. For the case of a single-line vertically undercrossing the pipeline, assuming that the pipeline and soil are continuous and elastic, the Peck formula is widely used [8]:

$$
\begin{aligned}
S & =S_{\max } \exp \left[-\frac{x^{2}}{2 i^{2}}\right], \\
S_{\max } & =\frac{V_{\text {loss }}}{i \sqrt{2 \pi}},
\end{aligned}
$$

where $S$ is the settlement at the distance $x$ from the centerline of the tunnel on the cross-section, $S_{\max }$ is the maximum ground surface settlement, and the settlement of the ground surface is described by the settlement tank width $i$ and the formation loss rate $V_{\text {loss. }}$. At the same time, equations (1) and (2) can be used to describe the settlement of a pipeline. Under certain conditions, the settlement of the ground surface can be used to estimate the settlement of a pipeline [25]. The interaction of pipeline-soil is relatively clear during single-tunnel construction. According to the previous analysis, when the parameters are easier to obtain, the analytical method can provide relatively simple and accurate results. It is necessary to consider the interaction of the tunnels when studying the settlement during twin-tunnel construction, especially when the tunnels are constructed in turn. At this time, either the analytical method is difficult to solve or the solution is more complicated. Therefore, it was planned to conduct research in conjunction with the Peck formula and pay more attention to the final settlement.

The calculation of the impact of twin-tunnel construction is more complicated and it needs to be discussed according to the situation. Specifically, based on the results of existing settlements $[26,27]$, the final settlement can be divided into three categories. If there is a maximum settlement and the settlement curve is symmetrical, then the settlement is called a $\mathrm{V}$-shaped settlement. If there are two maximum settlements (the two maximum settlements can be different), the settlement curve is W-shaped. Additionally, the U-shaped settlement (with a wider settlement center) is between the $\mathrm{V}$-shaped and the $\mathrm{W}$-shaped settlements. The final settlement of the ground surface and a pipeline is affected by many factors. For a V-shaped settlement, because of the overlap of the affected area of the excavation planes, an equivalent method can be used and the Peck formula can be applied. For a $\mathrm{W}$-shaped settlement, the Peck formula can be extended from a single-tunnel to a twin-tunnel [28]. When the right tunnel is constructed first, the final settlement curve can be calculated using the following equation:

$$
S=S_{\max s} \exp \left[-\frac{(x-0.5 L)^{2}}{2 i_{s}^{2}}\right]+S_{\max f} \exp \left[-\frac{(x+0.5 L)^{2}}{2 i_{f}^{2}}\right]
$$

where $S$ is the settlement at the distance $x$ from the centerline of the twin-tunnel on the cross-section, $S_{\max f}$ and $S_{\max s}$ are the maximum settlements corresponding to the twin-tunnel, $i_{f}$ and $i_{s}$ are the settlement tank widths caused by the construction of FT and ST, respectively, and $L$ is the twintunnel space. In equation (3), the formation loss rate $V_{\text {loss }}$ and the settlement tank width $i$ are used to calculate the settlement regardless of whether there is a pipeline, so the equation is still applicable to the existence of pipelines in the soil. When considering the impact of the FT construction on the ST, the values of $V_{\text {loss }}$ and $i$ corresponding to the twintunnel are different, and the maximum settlements $S_{\max f}$ and $S_{\max s}$ at the two locations are different.

\section{Project Overview}

This project was located between the High-speed Railway South Station and Chengkan Road Station in the Hefei No. 4 
metro line. The length of the shielding construction was $1060 \mathrm{~m}$. The twin-tunnel in this section contained two parallel circular tunnels with a centerline space $L$ of $15 \mathrm{~m}$, and the outer diameter $D$ of the tunnels was $6 \mathrm{~m}$. The shielding segments were $0.3 \mathrm{~m}$ thick and $1.5 \mathrm{~m}$ long. They were made of C50 concrete. The buried depth of the top of the twin-tunnel was about $8.9 \mathrm{~m}$. The twin-tunnel vertically undercrossed a rainwater pipeline with a diameter of $1.5 \mathrm{~m}$. The rainwater pipeline was made of reinforced concrete with a wall thickness of $0.1 \mathrm{~m}$. The upper surface of the pipeline was $4.5 \mathrm{~m}$ below the ground surface. The closest distance between the tunnels and the pipeline was $2.9 \mathrm{~m}$. The relative positional relationship between the tunnels and the pipeline is shown in Figure 1.

According to the geological survey report for the Highspeed Railway South Station and Chengkan Road Station, there were three main types of soil, as shown in Figure 1, including fill, clay, and silty clay. The tunnels and the pipeline were all located in the clay layer. The basic mechanical parameters related to the soil layer and the tunnels are shown in Table 1. The amount of water in the survey depth was poor, and the impact of groundwater was small, so the groundwater could be ignored in the simulation analysis.

\section{Three-Dimensional Numerical Model}

4.1. FEM Model. A three-dimensional numerical model was established with GTS/NX software, which has often been used in the excavation simulation $[29,30]$. The model of the shielding tunnels undercrossing the pipeline was established to simulate the whole process of the construction, and the sizes of the tunnels and the pipeline in the model were consistent with the actual sizes. Considering the boundary effect, the model was centered on the pipeline and twintunnel, and the size of the model was $80 \mathrm{~m} \times 75 \mathrm{~m} \times 40 \mathrm{~m}$. Automatic boundary conditions were selected. The upper surface was a free surface. The horizontal displacements on all sides were constrained, and the fixed constraint was applied at the bottom. The model size, the grid division, and the simulation of the shield driving are shown in Figure 2.

Before the twin-tunnel was excavated, the pipeline was first constructed and then the initial stress was cleared. During the simulation of the construction, the construction length of each step was the width of two segments, that is, $3.0 \mathrm{~m}$. The construction of a single tunnel contained 25 such steps. In each simulating step, the shield shell was placed first. Then, the segments were installed, and the grouting was synchronized. During the simulating, the digging pressure was applied perpendicularly to the excavation plane, the jacking force was applied parallel to the segments, and the grouting pressure was applied perpendicularly to the segment. In the simulating step, activation instructions were used to simulate construction, passivation instructions were used to simulate excavation, and change properties instructions were used to simulate grouting. According to the construction organization design of the section, the directions of the twin-tunnel shielding were the same during construction. After the construction of the right tunnel was completed, the construction of the left tunnel began.

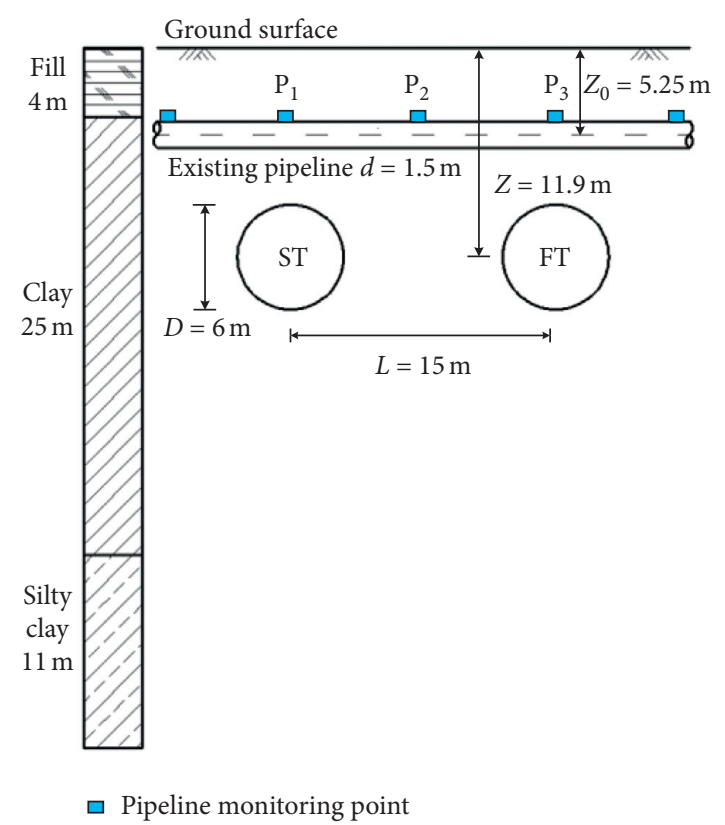

Figure 1: Profile of twin-tunnel crossing existing pipeline.

4.2. Material Model and Parameters. The basic mechanical parameters related to the soil layer and the shielding are shown in Table 1. For the three soil layers involved in the model, the modified Mohr-Coulomb yield criterion was used as the constitutive model, that is, the actual hardened soil model. The hardened soil model is widely used in the numerical analysis of excavation engineering because it can better reflect the stress-strain relationship when soil is unloaded [31, 32]. The constitutive relationship involved some parameters including the triaxial test secant stiffness $E_{50}^{\text {ref }}$, the tangent stiffness of the main compression loading test $E_{\text {oed }}^{\text {ref }}$, the unloading Elastic modulus $E_{\mathrm{ur}}^{\mathrm{ref}}$, the failure rate $\lambda$, and the reference pressure $P^{\text {ref }}$. The basic mechanical parameters of the soil were provided in the geological report. The parameters we needed mainly referred to the study of Shi et al. [30]. In [30], the data was obtained from experiments and verified with the field measured data. The partial parameters of the soil are given in Table 2.

All of the materials in the model except for the soil were isotropic linear elastic materials. The soil was simulated with the solid element. The shield shell, segments, and the pipeline were simulated with the plate element. For a more accurate simulation result, the model considered the digging pressure of the excavation plane, the horizontal jacking force, and the grouting pressure on the previous segments. The values of the three were the average values of the actual construction parameters. The digging pressure was $120 \mathrm{MPa}$, the jacking force was $100 \mathrm{MPa}$, and the grouting pressure was $0.2 \mathrm{MPa}$.

4.3. Verification of the Numerical Model. During the construction process, the settlements of the ground surface and the pipeline were measured and recorded. The measured settlements and the calculated settlements were compared and analyzed. Figure 3 shows the measured settlements and 
TABLE 1: Basic mechanical parameters related to the soil layer and the shielding.

\begin{tabular}{lcccccc}
\hline Material type & Thickness $(\mathrm{m})$ & Density $\left(\mathrm{kN} \cdot \mathrm{m}^{-3}\right)$ & Elastic modulus $(\mathrm{MPa})$ & Cohesion $(\mathrm{kPa})$ & Friction angle $\left(^{\circ}\right)$ & Poisson ratio \\
\hline Fill & 4 & 17.5 & 9 & 10 & 8 & 0.39 \\
Clay & 25 & 19.8 & 16.1 & 55 & 36 & 0.29 \\
Silty clay & 11 & 19.6 & 23 & - & -28 & - \\
Shield shell & 0.05 & 78 & $2.5 \times 105$ & - & - & 0.2 \\
Segment & 0.3 & 25 & $3.8 \times 103$ & - & - & 0.2 \\
Grouting layer & 0.05 & 20 & $2.0 \times 102$ & - & 0.3 \\
Concrete pipeline & 0.1 & 25 & & - & 0.2
\end{tabular}

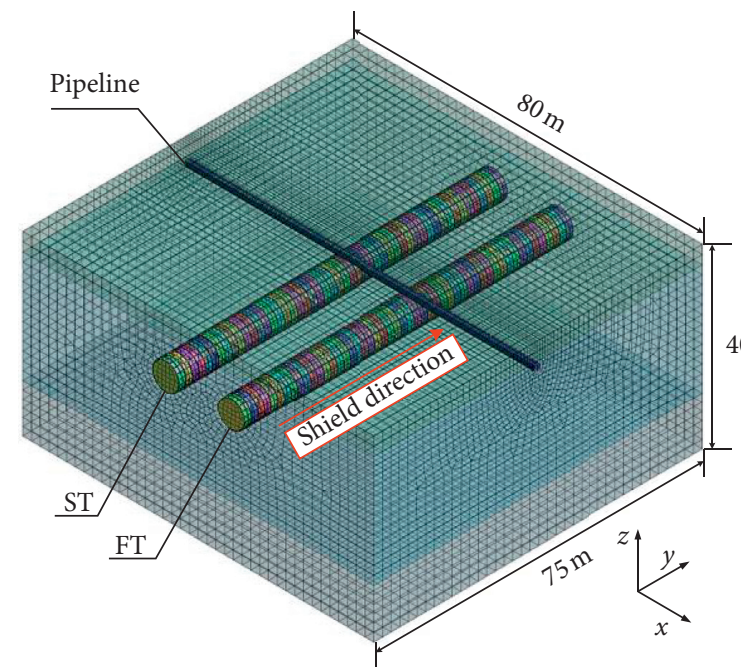

(a)

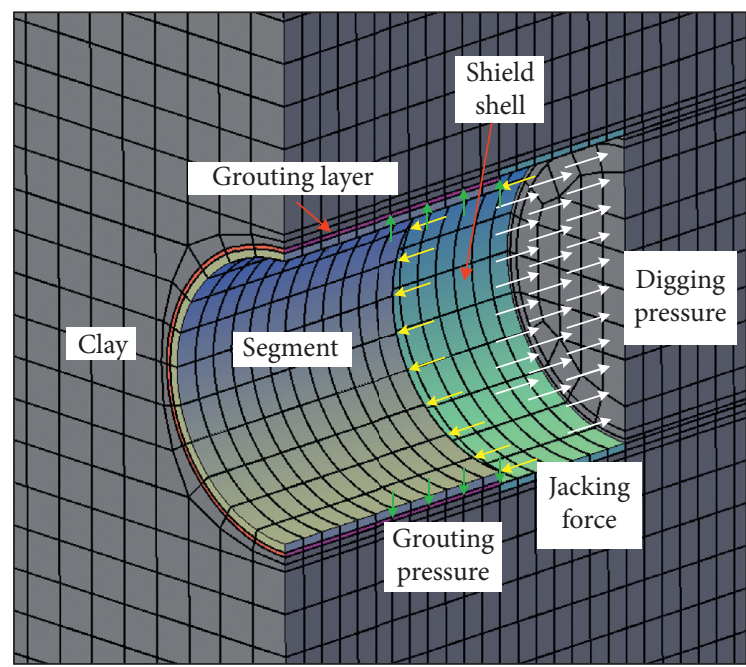

(b)

Figure 2: The finite-element model. (a) The mesh. (b) Simulation of shield driving.

TABLE 2: Mechanical parameters of the HS model of the soil layer.

\begin{tabular}{lcccccccc}
\hline Soil layer & $E_{50}^{\text {ref }}\left(\mathrm{kN} / \mathrm{m}^{2}\right)$ & $E_{\text {oed }}^{\text {ref }}\left(\mathrm{kN} / \mathrm{m}^{2}\right)$ & $E_{\text {ur }}^{\text {ref }}\left(\mathrm{kN} / \mathrm{m}^{2}\right)$ & $k_{0}^{\mathrm{NC}}$ & $\lambda$ & $P^{\text {ref }}\left(\mathrm{kN} / \mathrm{m}^{2}\right)$ & $n$ \\
\hline Fill & 8054 & 8054 & 24162 & 0.65 & 0.9 & 100 & 0.8 \\
Clay & 12167 & 12167 & 36501 & 0.39 & 0.9 & 100 & 0.7 \\
Silty clay & 13286 & 13286 & 39858 & 0.38 & 0.9 & 100 & 0.6 \\
\hline
\end{tabular}

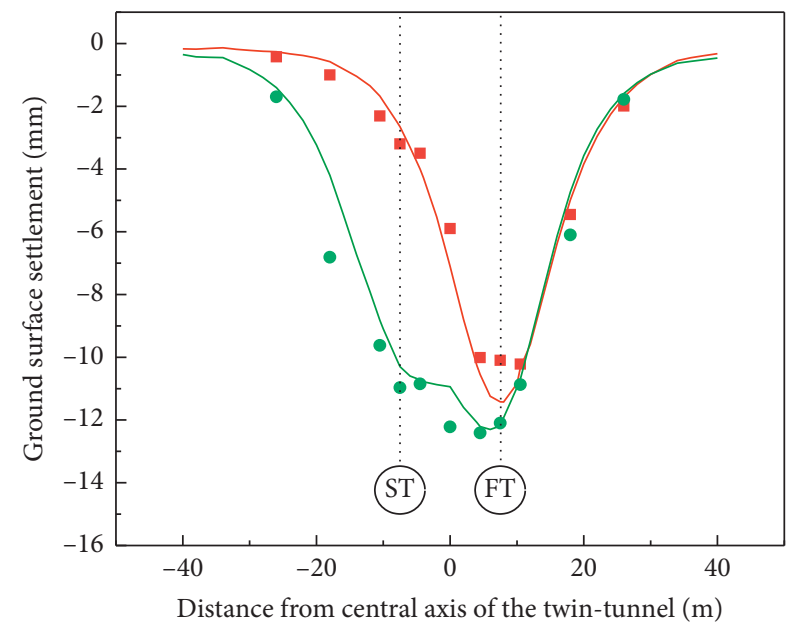

Calculated

— After FT construction

— After ST construction

Measured

- After FT construction

- After ST construction

(a)

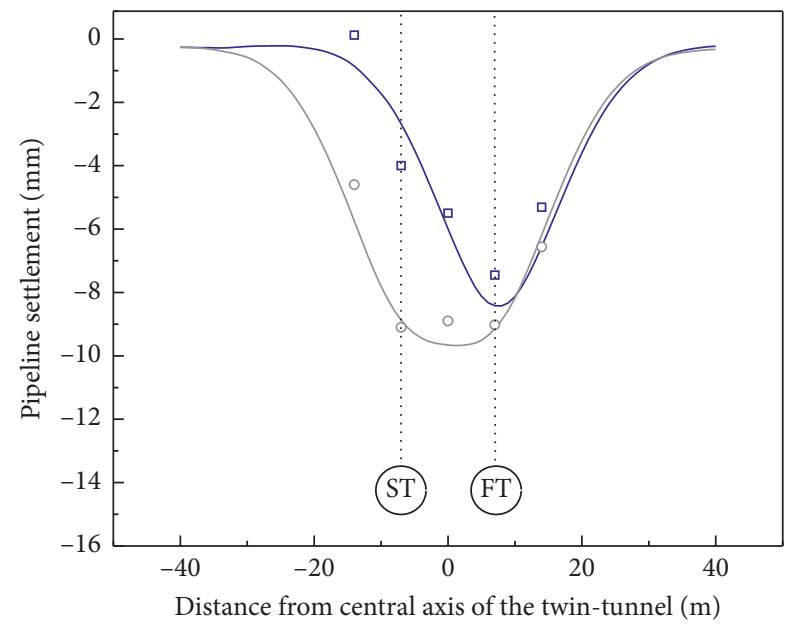

$\begin{array}{ll}\text { Calculated } & \text { Measured } \\ \text { — After FT construction } & \square \text { After FT construction } \\ \text { — After ST construction } & \circ \text { After ST construction }\end{array}$

(b)

Figure 3: Comparison of calculated and measured settlement development. (a) Ground surface settlement. (b) Pipeline settlement. 
the simulated calculation settlements after the FT construction and ST construction. According to Figure 3(a), after the FT construction was completed, the differences between the measured and calculated results of ground surface settlement were in the range of $0.1 \mathrm{~mm}-1.3 \mathrm{~mm}$. The measured maximum settlement was $-10.2 \mathrm{~mm}$, the calculated maximum settlement was $-11.4 \mathrm{~mm}$, and the difference between the two was $11 \%$. It can be seen from Figure 3(a) that the distribution of the two results was consistent. With consideration of the error of the measured result, it was believed that the calculated measured result was consistent with the measured result. After the ST construction was completed, the measured settlement and the calculated settlement were further developed. The final maximum measured settlement and the calculated settlement of the ground surface were $-12.4 \mathrm{~mm}$ and $-12.2 \mathrm{~mm}$, respectively. The two were basically the same with a $2 \%$ difference, and the positions of maximum settlements were consistent. Through the above analysis, we found that the measured settlement and the calculated settlement curve had the same shape, but the measured result had a larger settlement range. This might have been due to external disturbance factors such as the vehicle dynamic loads and the construction loads above the ground. Figure $3(\mathrm{~b})$ shows the comparison of the measured settlements and the calculated settlements of the pipeline. This comparison showed that after the FT construction and after the ST construction, although there were some differences between the measured settlements and the calculated settlements, the settlement distributions of the two were consistent. It was assumed in the model that the pipeline was continuous, but in practice it was not, and this was one of the reasons for the differences. The analysis of the measured and simulated settlement values showed that the calculation results of the model were credible. Therefore, further analysis could be made based on the results of this model.

\section{Analysis of Results}

5.1. Ground Surface Settlement. Based on the calculated results of the above model, a detailed analysis of the settlement of the ground surface was necessary. In the subsequent analysis, "-" indicated that the excavation plane had not yet reached the pipeline, " $0 \mathrm{~m}$ " indicated that the excavation plane was directly below the pipeline, and "+" indicated that the excavation plane had undercrossed the pipeline. The direction of the pipeline extension was recorded as the $x$-axis, and the direction of the shielding tunnel was recorded as the $y$-axis. The FT centerline was at $x=7.5 \mathrm{~m}$, and the ST centerline was at $x=-7.5 \mathrm{~m}$.

Figure 4 shows the settlement curve of the ground surface above the pipeline during the FT construction. When the excavation plane had not yet reached the pipeline and it was a long distance from the pipeline, the ground above the pipeline was not affected. When the excavation plane continued to approach, the ground surface began to settle. Figure 4 shows that when the excavation plane was $15 \mathrm{~m}$ away from the pipeline $(y=-15 \mathrm{~m})$, significant settlement began to appear on the ground above the FT centerline. As the construction continued, the FT excavation plane gradually approached the pipeline, the settlement of the ground surface gradually increased, and the settlement was symmetrically distributed. When the excavation plane was directly below the pipeline $(y=0 \mathrm{~m})$, the maximum settlement of the ground surface reached $4.9 \mathrm{~mm}$. When the excavation plane had undercrossed the pipeline and was $15 \mathrm{~m}$ away from the pipeline $(y=+15 \mathrm{~m})$, the ground surface settlement was essentially stable. The maximum settlement of the ground surface was $11.4 \mathrm{~mm}$ after the completion of the FT construction. The maximum settlement occurred on the FT centerline $(x=-7.5 \mathrm{~m})$. During the FT construction, the rate of ground surface settlement development gradually increased in the beginning and then gradually decreased after undercrossing the pipeline. Finally, the settlement did not increase. The settlement developed the fastest in the range of $-6 \mathrm{~m}$ to $6 \mathrm{~m}$. The settlement generated in this range accounted for $52 \%$ of the total settlement during the FT construction. Therefore, more attention had to be paid to the excavation around the pipeline.

After the FT construction was completed, the settlement of the ground surface continued to be analyzed during the ST construction. Figure 5 shows the settlement curve during the ST construction. As the figure shows, during the ST construction, the developments of ground surface settlements on both sides of the ST centerline were inconsistent. The settlement range and the settlement value on the left side were larger. Furthermore, the settlement on the right side of the FT tunnel $(x>7.5 \mathrm{~m})$ remained basically unchanged during the ST construction. This could be explained by the construction disturbance. The ground surface on the right side of the FT tunnel has been greatly disturbed during the FT construction. During the ST construction, because of the long distance and small disturbance, the secondary disturbance did not cause further development of the settlement. The ground surface inside the twin-tunnel area was affected by two disturbances. The effects of the two disturbances were different. It can be seen from the figure that the second disturbance caused by the ST construction had less influence. The ground surface settlement around the ST also remained unchanged at the beginning, and the settlement did not increase until the excavation plane was $9 \mathrm{~m}$ away from the pipeline $(y=-9 \mathrm{~m})$. Subsequently, the ground surface settlement gradually increased with the progress of the ST construction, and the location of the maximum settlement slowly approached the ST. After the excavation plane had undercrossed the pipeline and was $9 \mathrm{~m}$ away from the pipeline $(y=+9 \mathrm{~m})$, the settlement was essentially stable. After the ST construction was completed, that is, when the entire twin-tunnel was completed, the maximum settlement of the ground surface was $12.3 \mathrm{~mm}$, and the maximum settlement was located inside the twin-tunnel area $(x=5 \mathrm{~m})$.

After comparing and analyzing the development of the ground surface settlement during the FT and ST construction, it was evident that the FT construction had a greater impact on the settlement of the ground surface. The influence range was wider and the settlement developed more quickly. For the three points on the ground surface on $x=-7.5 \mathrm{~m}, 0 \mathrm{~m}$, and $7.5 \mathrm{~m}$ from left to right, the settlement 


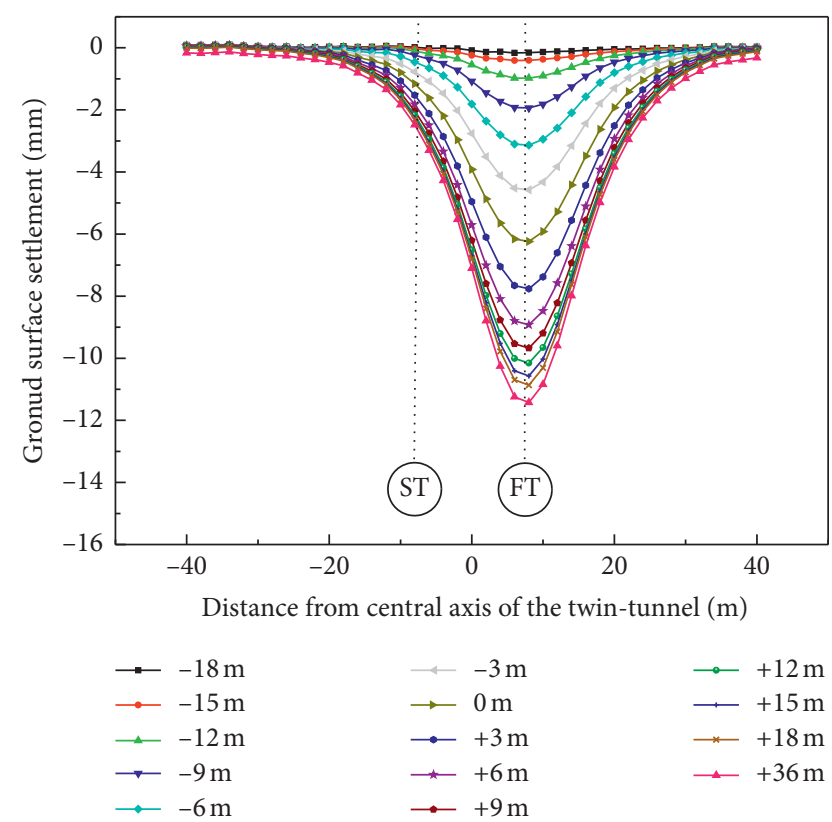

FIGURE 4: The ground surface settlement directly above the pipeline during the FT construction.

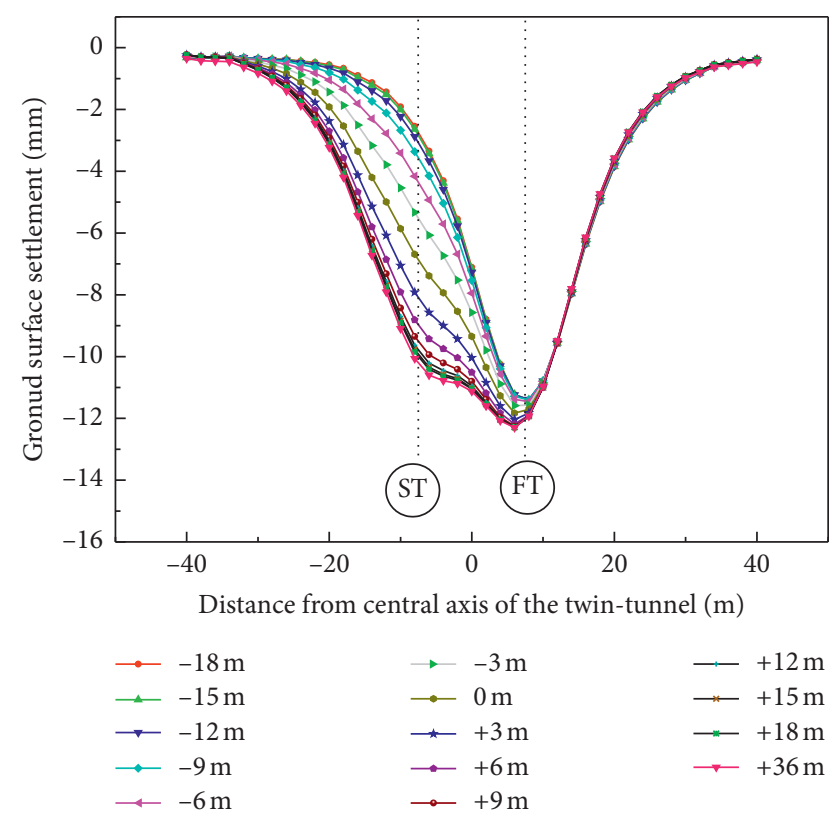

FIGURE 5: The ground surface settlement directly above the pipeline during the ST construction.

caused by the FT construction accounted for $28 \%, 64 \%$, and $94 \%$ of the total settlement, respectively. The ST construction could only increase the ground surface settlement directly above the ST, and it had almost no influence on the ground surface above the FT.

5.2. Pipeline Settlement. Figure 6 shows the settlement of the pipeline during the FT construction and the ST construction. As the figure shows, the settlement development of the pipeline was consistent with the settlement development of the ground surface. During the FT construction, the settlement of the pipeline was centered on the FT centerline, and as the construction progressed, the settlement of the pipeline continued to increase. After the completion of the FT construction, the settlement curve was symmetrically distributed. The maximum settlement was $8.4 \mathrm{~mm}$, which occurred on the FT centerline. Similar to the development of the ground surface settlement, the pipeline settlement continued to develop during the ST construction. The settlement center slowly approached the ST. After the ST construction was completed, the maximum settlement of the ground surface was $9.7 \mathrm{~mm}$ and the maximum settlement was located inside the twin-tunnel area $(x=1 \mathrm{~m})$. At the same time, there were some differences between the settlements of the ground surface and the pipeline. The final settlement curve of the ground surface was no longer symmetrical, but the final settlement curve of the pipeline remained essentially symmetrical. This difference in settlement curves between the ground surface and the pipeline was due to the difference in the stiffness. The stiffness of the pipeline was greater and the pipeline had a greater ability to resist construction disturbance. The effect of the difference of the stiffnesses on the settlements is discussed later in Section 6.

Three points $\mathrm{P}_{1}, \mathrm{P}_{2}$, and $\mathrm{P}_{3}$ (as shown in Figure 1) on the pipeline were selected. Figure 7 shows the settlement developments of the three points during the twin-tunnel construction. As shown in the figure, during the FT construction, the settlement on the pipeline developed in three stages: stage I: when the excavation plane had not reached $y=15 \mathrm{~m}$ ( -36 to $-15 \mathrm{~m})$, the settlement was stable and unchanged; stage II: in the range of $-15 \mathrm{~m}$ to $+18 \mathrm{~m}$, the settlement increased linearly; and stage III: the settlement developed slowly until it stabilized after the excavation plane was $18 \mathrm{~m}$ away from the pipeline $(+18 \mathrm{~m}$ to $+36 \mathrm{~m})$. The settlement of the pipeline was produced mainly in stage II. In stage II, the settlement increased linearly with different rates at different locations. The closer the location was to the excavation plane, the faster the settlement development was. During the ST construction, the settlement developments of the three points on the pipeline were the same as those of the FT construction. Compared with the FT construction, in stage $\mathrm{II}^{\prime}$, the time became shorter and the settlement developments were less. The settlement of $\mathrm{P}_{1}$ developed the fastest and increased the most. After the ST construction, the final settlement differences between three points were reduced, and the settlements were all approximately $9 \mathrm{~mm}$. The settlement above the centerline of the twin-tunnel $\left(\mathrm{P}_{2}\right)$ was the largest, and the settlement above the FT centerline $\left(\mathrm{P}_{1}\right)$ was the smallest.

\section{Study of the Influence of the Twin-Tunnel Undercrossing the Pipeline}

Currently, the design and the construction of city tunnels mostly involve two parallel tunnels. To avoid excessive disturbance, the construction scheme of a twin-tunnel with the same shielding directions and different shielding time is widely adopted [33]. The excavation planes of the two 


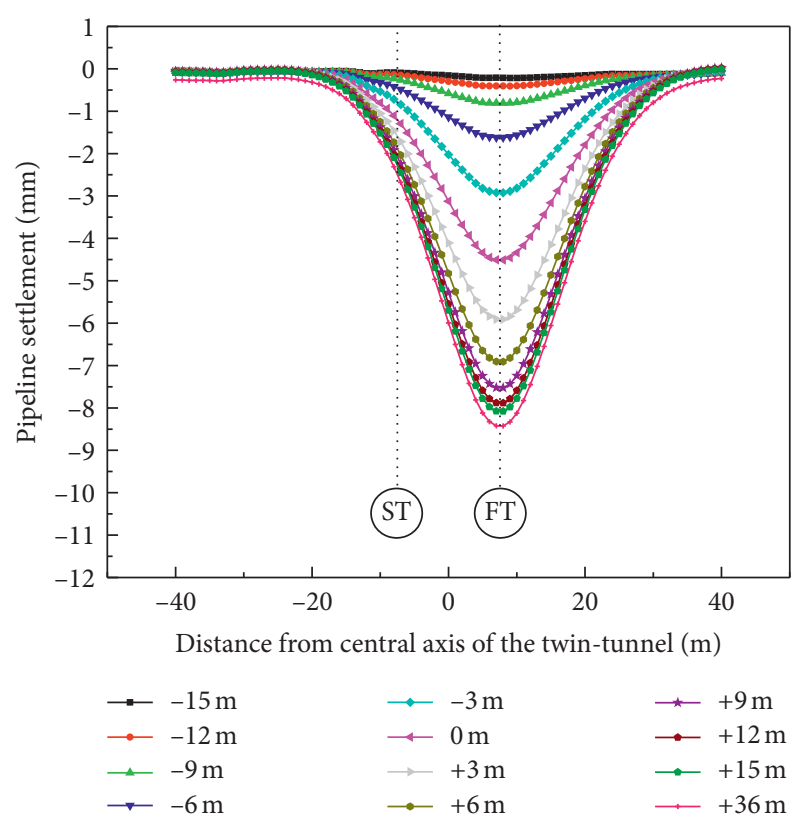

(a)

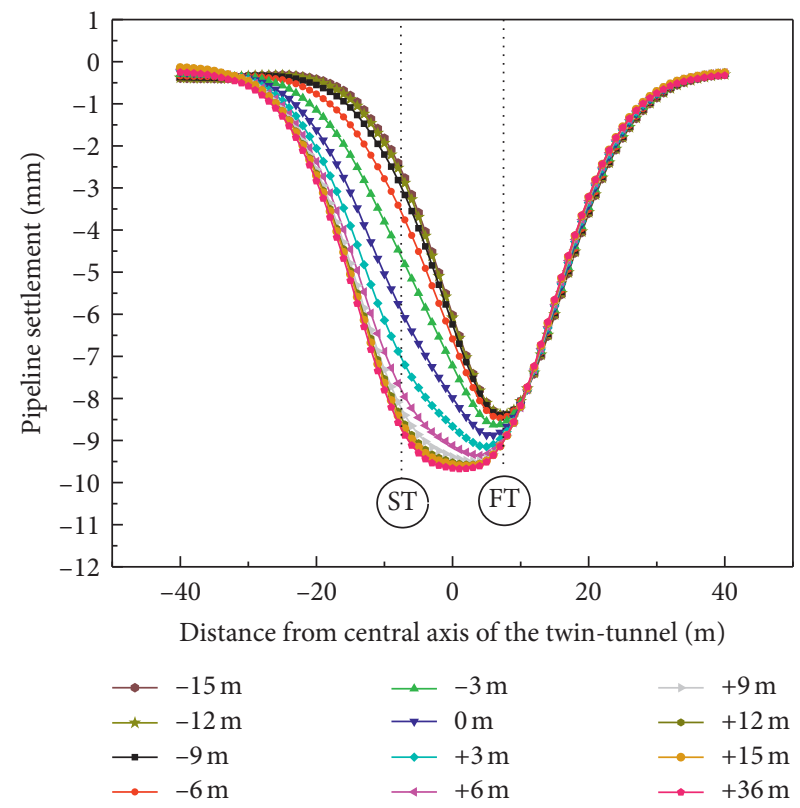

(b)

Figure 6: Settlement of the pipeline during construction. (a) FT construction. (b) ST construction.

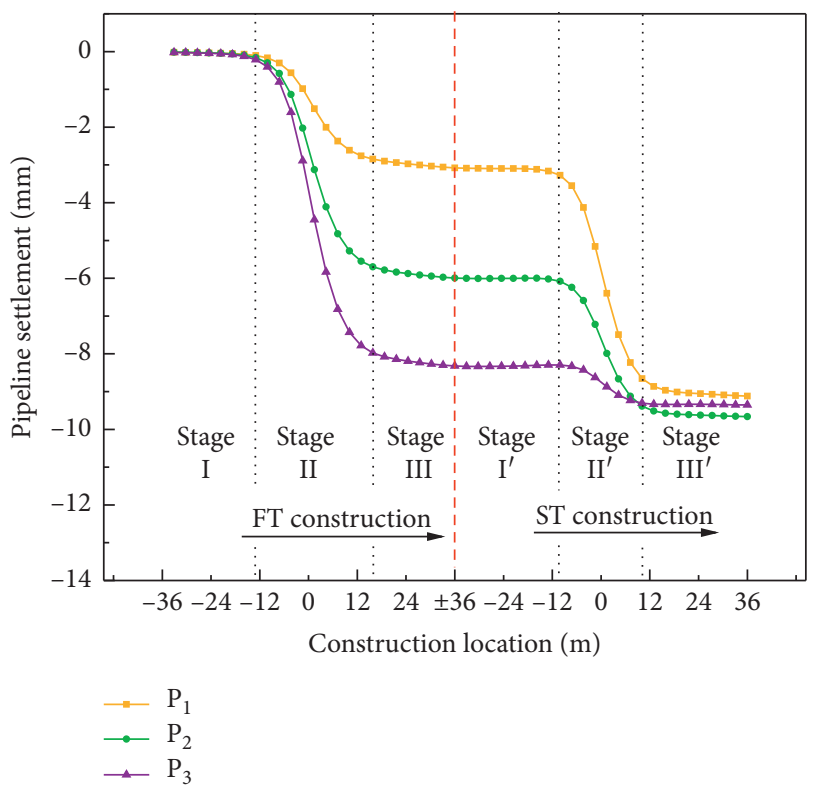

FIGURE 7: Settlement change of three points on the pipeline during the twin-tunnel construction.

tunnels always maintain a certain distance during construction. From the above analysis, it was evident that the ST construction caused a second disturbance to the stabilized soil and pipeline. The Earth pressure was redistributed and the settlement changed accordingly. At that time, the influence of the twin-tunnel construction on the ground surface and the pipeline was more complicated.

Many factors determined the settlement of the ground surface and the pipeline. These factors could be divided into two types. One type of factor involved tunnel parameters such as the tunnel depth, the twin-tunnel space, and the construction method. The other type involved the pipeline parameters, such as the size and the stiffness of the pipeline, the pipeline-soil distance, and the pipeline-soil relative stiffness. These parameters determined the formation loss rate $V_{\text {loss }}$ and the settlement tank width $i$ ( $V_{\text {loss }}$ determined the depth and $i$ determined the width [34]). Considering the noted factors, the key parameters including the twin-tunnel space $L$ and the pipeline-soil relative stiffness $K$ were selected for further study.

6.1. Influence of the Twin-Tunnel Space L on the Settlements. Considering the actual project, the twin-tunnel space $L$ was taken as $9 \mathrm{~m}(1.5 \mathrm{D}), 12 \mathrm{~m}(2 \mathrm{D}), 15 \mathrm{~m}(2.5 \mathrm{D}), 18 \mathrm{~m}(3 \mathrm{D})$, and $21 \mathrm{~m}(3.5 \mathrm{D})$ for calculation and analysis. The other variables remained constant during the calculation.

Figure 8 shows the settlement curves of the ground surface and the pipeline at different spaces in the twintunnel. For different spaces, the settlement developments during the FT construction were the same, and the final maximum settlement values were the same. The spaces in the twin-tunnel were different, the impact of the ST construction was significantly different, and the final settlements after ST construction were significantly different. Figure 8(a) shows the final settlement curves of the ground surface after the ST construction. From the figure, it could be seen that the larger the twin-tunnel space was, the larger the range of the ground surface settlement was. All of the maximum settlements of the ground surface occurred in the range of $-1 / 2 L-1 / 2 L$. Additionally, as the space increased, the location of the maximum settlement became closer to the FT centerline. Out the range of $-L-\mathrm{L}$, the greater the space was, the greater the settlement of each point on the ground surface was. 


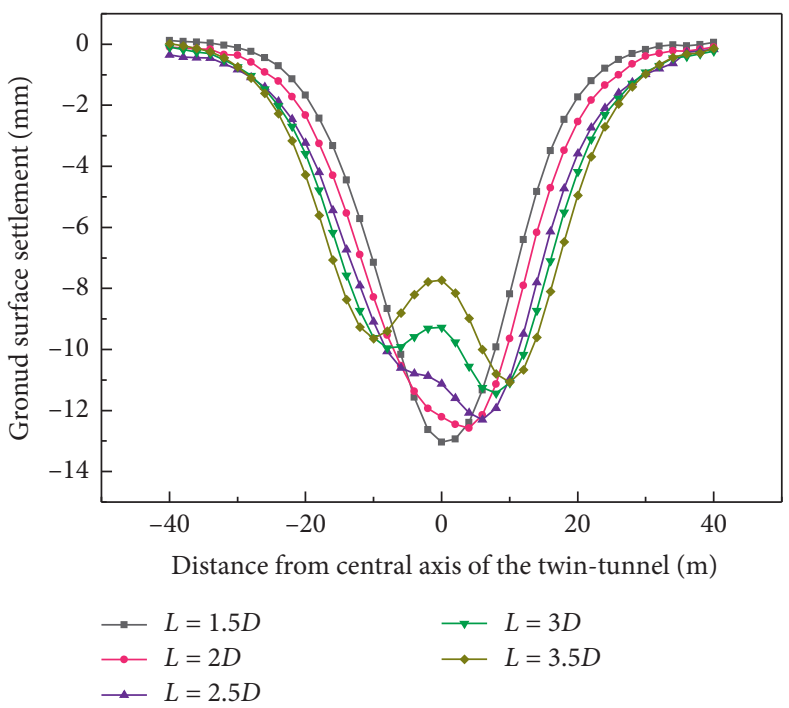

(a)

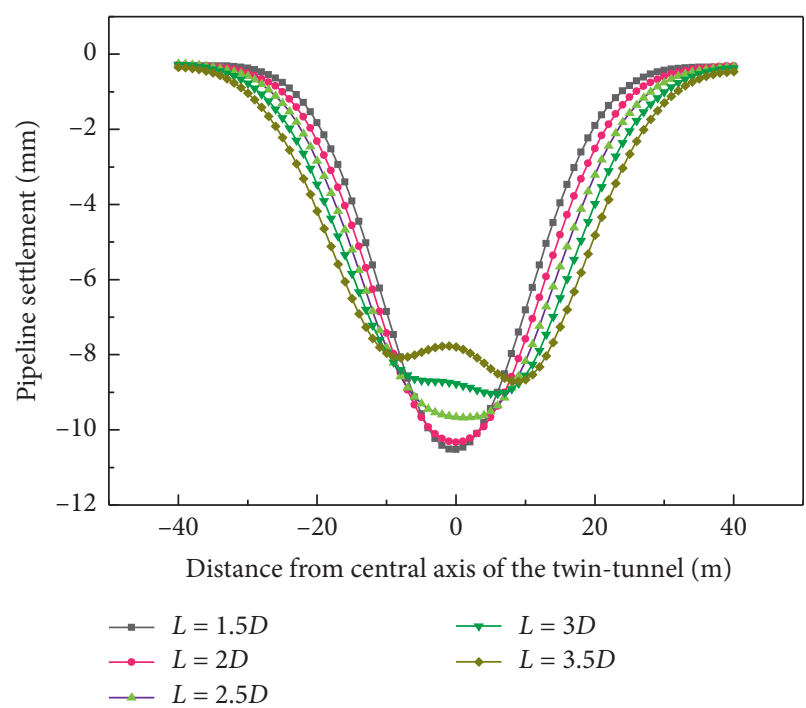

(b)

FIgURE 8: The settlement during ST construction with different spaces. (a) Ground surface settlement. (b) Pipeline construction.

Between $-L-\mathrm{L}$, as the space increased, the settlement of the ground surface gradually decreased, and the settlement curve had a significant difference. According to the study of $\mathrm{Xu}$ [9], we could judge whether the curve conformed to the Gaussian distribution through the linear relationship of $\ln \left(S / S_{\max }\right) \sim x^{2}$ and judge whether the curve was symmetric through the slope. Through the above analysis, it could be found when $L=1.5 \mathrm{D}$, the settlement curve conformed to a Gaussian distribution, which could be calculated with the Peck formula. When $L=2 D$, the settlement curve was no longer symmetrical. When $L=2.5 \mathrm{D}$, the settlement curve approached the $\mathrm{W}$-shape. When the tunnel space continued to increase to $3 D$, the ground surface settlement curve was obviously $\mathrm{W}$-shaped. The figure shows that the twin-tunnel space continued to increase, and the difference between the two maximum settlements of the $\mathrm{W}$-shaped settlement curve gradually decreased. It could be speculated that when the twin-tunnel space was sufficiently large, the two maximum settlements would be the same, and the settlement curve of the ground surface would be a standard $\mathrm{W}$-shape. In that case, the construction of the two tunnels would not affect each other, and the twin-tunnel construction could be calculated separately and superimposed.

The settlements of the pipeline at different spaces are shown in Figure 8(b). Similarly, out the range of $-L-L$, as the space Lincreased, the settlement of the corresponding point on the pipeline increased and the settlement range increased. In the range of $-L-\mathrm{L}$, the settlement of the pipeline decreased with the increase of the space, and the shape of the settlement curve was different. When $L=1.5 D, 2 D, 2.5 D$, the settlement curve of the pipeline was V-shaped. When $L=3 D$, the settlement curve of the pipeline could be regarded as $U$-shaped, and when the space continued to increase to $3.5 \mathrm{D}$, the settlement curve appeared to have two settlement centers above the twin-tunnel, corresponding to the two different maximum settlements. The settlement curve was obviously $\mathrm{W}$-shaped.
Table 3 provides the statistics of the settlement characteristics of the ground surface and the pipeline for different twin-tunnel spaces. By comparing the settlement of the ground surface with the settlement of the pipeline, it could be found that the settlement range and the settlement value of the pipeline were smaller than the settlement of the ground surface for each space. Additionally, the location of the maximum settlement of the ground surface was closer to the FT centerline. For the same space, when the pipeline settlement curve was $\mathrm{W}$-shaped, the ground surface settlement curve was definitely $\mathrm{W}$-shaped. Furthermore, when the ground surface settlement curve was not $\mathrm{W}$-shaped, the pipeline settlement was definitely not $\mathrm{W}$-shaped. That is, the ground surface was more prone to have a $\mathrm{W}$-shaped settlement curve than the pipeline was. When the settlement curve was $\mathrm{W}$-shaped, the difference between the two maximum settlements of the pipeline was smaller than that of the ground surface. The settlement difference between the ground surface and the pipeline in the above analysis was due to the difference in the stiffness.

6.2. Influence of the Stiffness of the Pipeline and Soil on the Settlements. When considering the impact of the stiffness on the settlement, many factors such as the elastic modulus of the soil, the cross-sectional shape, area, and elastic modulus of the pipeline had to be considered. To facilitate the research, the parameter $K$ was defined as the pipeline-soil relative rigidity stiffness according to the study of Vorster et al. [35]:

$$
K=\frac{\mathrm{EI}}{i_{f}^{3} r_{0} E_{s}}
$$

where EI is the stiffness of the pipeline, $i_{f}$ is the settlement tank width caused by the FT construction, $r_{0}$ is the outer radius of the pipeline, and $E_{s}$ is the elastic modulus of the 
TABLE 3: Settlements of the ground surface and the pipeline with different spaces.

\begin{tabular}{|c|c|c|c|c|c|c|c|c|}
\hline \multirow[t]{2}{*}{$L$} & \multicolumn{2}{|c|}{$\begin{array}{l}\text { Settlement range } \\
\text { width }(\mathrm{m})\end{array}$} & \multicolumn{2}{|c|}{ Maximum settlement (mm) } & \multicolumn{2}{|c|}{$\begin{array}{l}\text { Maximum settlement } \\
\text { location }(\mathrm{m})\end{array}$} & \multicolumn{2}{|c|}{$\begin{array}{l}\text { Settlement curve } \\
\text { shape }\end{array}$} \\
\hline & Surface & Pipeline & Surface & Pipeline & Surface & Pipeline & Surface & Pipeline \\
\hline $1.5 \mathrm{D}$ & 60 & 52 & -13.0 & -10.5 & $x=0$ & $x=0$ & $\mathrm{~V}$ & $\mathrm{~V}$ \\
\hline $2 D$ & 65 & 54 & -12.6 & -10.3 & $x=4$ & $x=0$ & $\mathrm{U}$ & $\mathrm{V}$ \\
\hline $2.5 \mathrm{D}$ & 68 & 58 & -12.3 & -9.7 & $x=6$ & $x=1$ & $\mathrm{U}$ & $\mathrm{U}$ \\
\hline $3 D$ & 72 & 62 & $-11.4(-9.9)$ & -9.0 & $x=8(-8)$ & $x=6$ & $\mathrm{~W}$ & $\mathrm{U}$ \\
\hline $3.5 \mathrm{D}$ & 73 & 66 & $-11.1(-9.6)$ & $-8.7(-8.1)$ & $x=10(-10)$ & $x=8(-8)$ & $\mathrm{W}$ & W \\
\hline
\end{tabular}

Note: there were two maximum settlements in the $\mathrm{W}$-shape, and the other maximum settlement was in the bracket.

soil. Combined with the research of Zhao et al. [25], $i_{f}$ is the width of the ground surface settlement tank.

In actual engineering, pipelines for different purposes have different sizes and materials. In general, common pipelines include polyvinyl chloride (PVC) pipelines (elastic modulus of $2.5 \mathrm{GPa}$ ), concrete pipelines (elastic modulus of $25 \mathrm{GPa}$ ), cast iron pipelines (elastic modulus of $150 \mathrm{GPa}$ ), and steel pipelines (elastic modulus of $200 \mathrm{GPa}$ ). When the twin-tunnel space was maintained at $15 \mathrm{~m}$, the four relative stiffnesses were used for calculation. The settlement curves after the completion of the FT construction and the ST construction are shown in Figure 9.

During the FT construction, the larger the stiffness of the pipeline was, the smaller the settlement of the pipeline was. The width of the settlement area was between $10 \mathrm{D}$ and $16 \mathrm{D}$. The settlement characteristics of the ground surface were similar to those of the pipeline. The characteristics of the ground surface settlement for different stiffnesses were different, and the settlement tank width $i_{f}$ was different. The values of $i_{f}$ for different stiffness conditions are shown in Table 4. The settlements of the ground surface after the ST construction are shown in Figure 9(a). When the pipeline-soil relative stiffness $K$ was small, the settlement of the ground surface was $\mathrm{W}$-shaped and the settlement was large. As the pipeline-soil relative rigidity stiffness increased, the settlement curve gradually developed toward a U-shape. Because of the small stiffness of the soil, it was difficult for the ground surface to have a V-shaped settlement. The settlement curves of the pipeline after the ST construction with different pipeline-soil relative stiffnesses are shown in Figure 9(b). When $K$ was small, the settlement curve of the pipeline was the same as the settlement of the ground surface. To some extent, the settlement of the pipeline could be replaced by the ground surface settlement. When $K$ increased to 1.9 , the pipeline settlement was $\mathrm{U}$-shaped. When $K$ continued to increase, the pipeline settlement was V-shaped. The settlement characteristics of the ground surface and the pipeline are given in Table 4 .

6.3. Judgment of the Shape of the Settlement Curve. Based on this analysis, it was obvious that the settlement curves of the ground surface and the pipeline had different characteristics at different spaces and stiffnesses. To better understand the settlement characteristics of the ground surface and the pipeline, 20 sets of models with different spaces $(L=1.5 D, 2 D, 2.5 D, 3 D, 3.5 D)$ and different pipelinesoil relative stiffnesses $(K=0.4,1.9,6.6,8.8)$ were calculated. The shapes of the settlement curves of the ground surface and the pipeline after the ST construction are summarized in Table 5. As shown in Table 5, as the space increased and the relative stiffness decreased, the settlement curves of the ground surface and the pipeline developed from V-shaped to $\mathrm{W}$-shaped. When $L \leq 1.5 \mathrm{D}$, the ground settlement was $\mathrm{V}$-shaped for the four kinds of stiffnesses, and the construction disturbance of the twin-tunnel could be equivalently calculated. When the space increased, the settlements of the ground surface and the pipeline began to differ. When $L \geq 3 D$, the settlement of the surface was $\mathrm{W}$-shaped for each stiffness. When the space $L$ was between $1.5 D$ and $3 D$, the shape of the settlement curve depended on the relative stiffness. For the settlement of the pipeline, when $L \leq 2 D$ or $K \geq 6.6$, the settlement curve was V-shaped or U-shaped. The settlement of the pipeline was $\mathrm{W}$-shaped only when the space was large, and the relative stiffness was small. Table 5 also shows that, for the two factors of the twin-tunnel space and the pipeline-soil relative rigidity, the twin-tunnel space had a greater impact on the settlement. Additionally, when the change of the relative stiffness was small, the effect on the settlement was negligible.

6.4. Further Study of the W-shaped Settlement. Based on this research, it was found that the settlement curves of the ground surface and the pipeline could be divided into $\mathrm{W}$-shaped, U-shaped, and V-shaped settlement curves because of their different spaces and stiffnesses. The V-shaped and U-shaped settlements only had one maximum settlement, but the $\mathrm{W}$-shaped settlement had two maximum settlements. More attention was paid to the maximum settlements. Through the previous analysis, it could be known that when the $\mathrm{W}$-shaped settlement occurred, the two maximum settlements appeared on the centerlines of the twin-tunnel. Because of the greater stiffness of the pipeline, it was difficult for $\mathrm{W}$-shaped settlement to occur in the actual project. Therefore, only the $\mathrm{W}$-shaped settlement of the ground surface was discussed. The $\mathrm{W}$-shaped settlement meant that the settlement curve had two maximum settlements, namely, $S_{\max f}$ and $S_{\max s}$ in equation (3). Defining $C=S_{\max s} / S_{\max f}, C$ reflected the impacts of the FT construction and the ST construction.

6.4.1. Influence of the Twin-Tunnel Space on the W-Shaped Settlement. Table 5 shows that when the pipe-soil relative stiffness $K$ was 0.4 and the space $L$ was $2 D, 2.5 D, 3 D$, or 


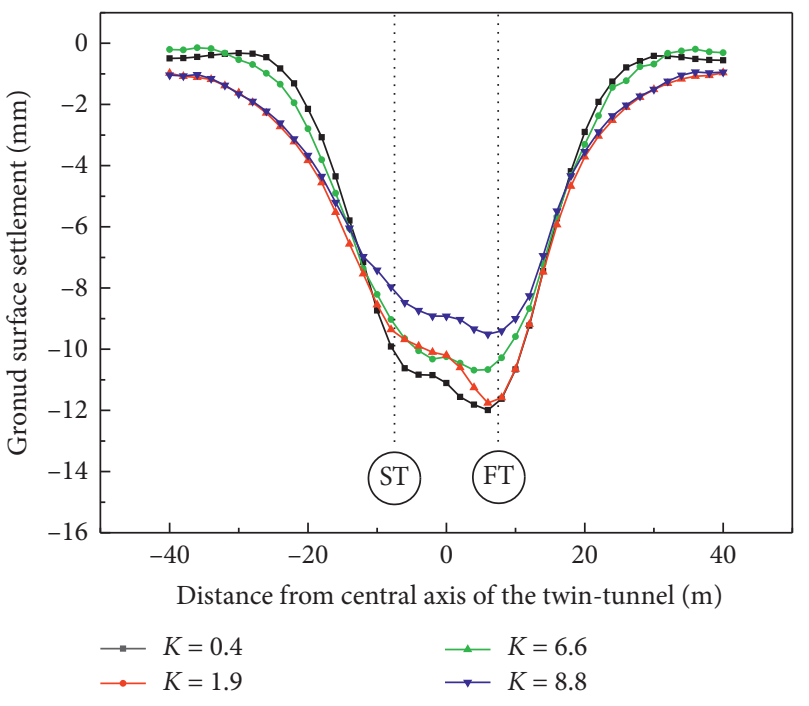

(a)

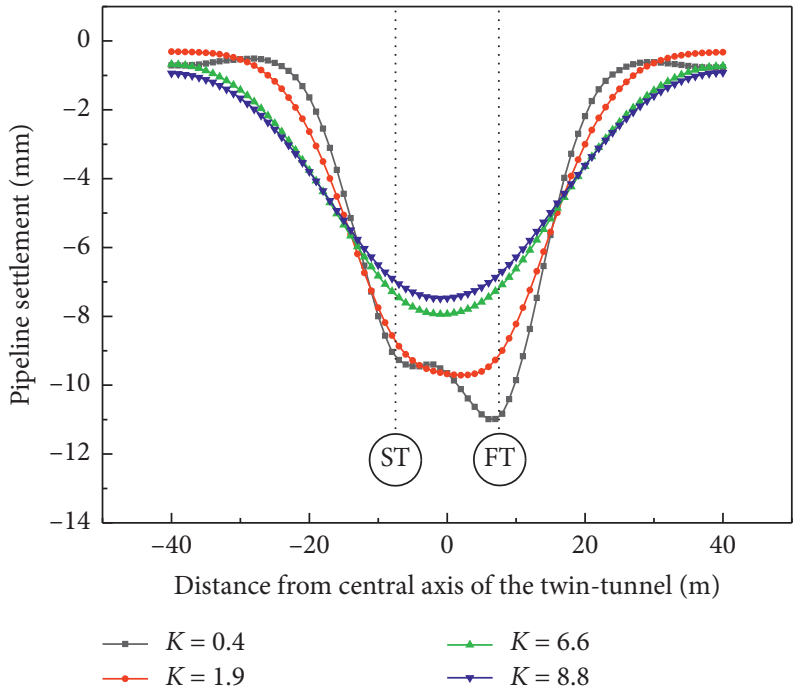

(b)

Figure 9: The settlement during the ST construction with different relative stiffnesses. (a) Ground surface settlement. (b) Pipeline construction.

TABLE 4: Settlements of ground surface and the pipeline with different rigidities.

\begin{tabular}{lccccc}
\hline Material & $\begin{array}{c}E \\
(\mathrm{GPa})\end{array}$ & $\begin{array}{c}i_{f} \\
(\mathrm{~m})\end{array}$ & $K$ & $\begin{array}{c}\text { Surface } \\
\text { settlement }\end{array}$ & $\begin{array}{c}\text { Pipeline } \\
\text { settlement }\end{array}$ \\
\hline PVC & 2.5 & 8 & 0.4 & $\mathrm{~W}$ & $\mathrm{~W}$ \\
Concrete & 25 & 9 & 1.9 & $\mathrm{~W}$ & $\mathrm{U}$ \\
Cast iron & 150 & 11 & 6.6 & $\mathrm{~W}$ & $\mathrm{~V}$ \\
Steel & 200 & 12 & 8.8 & $\mathrm{U}$ & $\mathrm{V}$ \\
\hline
\end{tabular}

TABLE 5: Settlement curve shapes for the ground surface and the pipeline.

\begin{tabular}{lccccc}
\hline$K$ & \multicolumn{5}{c}{$L$} \\
& $1.5 D$ & $2 D$ & $2.5 D$ & $3 D$ & $3.5 D$ \\
\hline 0.4 & $\mathrm{~V}(\mathrm{~V})$ & $\mathrm{W}(\mathrm{U})$ & $\mathrm{W}(\mathrm{U})$ & $\mathrm{W}(\mathrm{W})$ & $\mathrm{W}(\mathrm{W})$ \\
1.9 & $\mathrm{~V}(\mathrm{~V})$ & $\mathrm{U}(\mathrm{V})$ & $\mathrm{U}(\mathrm{U})$ & $\mathrm{W}(\mathrm{U})$ & $\mathrm{W}(\mathrm{W})$ \\
6.6 & $\mathrm{~V}(\mathrm{~V})$ & $\mathrm{V}(\mathrm{V})$ & $\mathrm{U}(\mathrm{V})$ & $\mathrm{W}(\mathrm{U})$ & $\mathrm{W}(\mathrm{U})$ \\
8.8 & $\mathrm{~V}(\mathrm{~V})$ & $\mathrm{V}(\mathrm{V})$ & $\mathrm{U}(\mathrm{V})$ & $\mathrm{W}(\mathrm{V})$ & $\mathrm{W}(\mathrm{U})$ \\
\hline
\end{tabular}

Note: the curve shape of the pipeline settlement is in the bracket.

3.5 D, the ground surface settlements were $\mathrm{W}$-shaped. This set of data was further analyzed. The statistics of the maximum settlements of the ground surface for the same stiffness and different spaces are shown in Figure 10. After the FT construction, the maximum settlement $\left(S_{\max f}\right)$ of the ground surface was $11.5 \mathrm{~mm}$. After the ST construction, $S_{\max f}$ increased further, and another maximum settlement $S_{\max s}$ was formed. From Figure 10, it could be inferred that when $L<2 D$, the two maximum settlements were almost equal; that is, $C=1$. In fact, the settlement might be $\mathrm{U}$-shaped, and this was consistent with the U-shaped settlement characteristics. Figure 10 shows that as the space increased, $S_{\max f}$ and $S_{\max s}$ both decreased. At the same time, for the spaces of $2 \mathrm{D}, 2.5 \mathrm{D}, 3 \mathrm{D}$, and $3.5 \mathrm{D}, \mathrm{C}$ was 0.98 , $0.89,0.85$, and 0.85 , respectively. Within a certain range, as

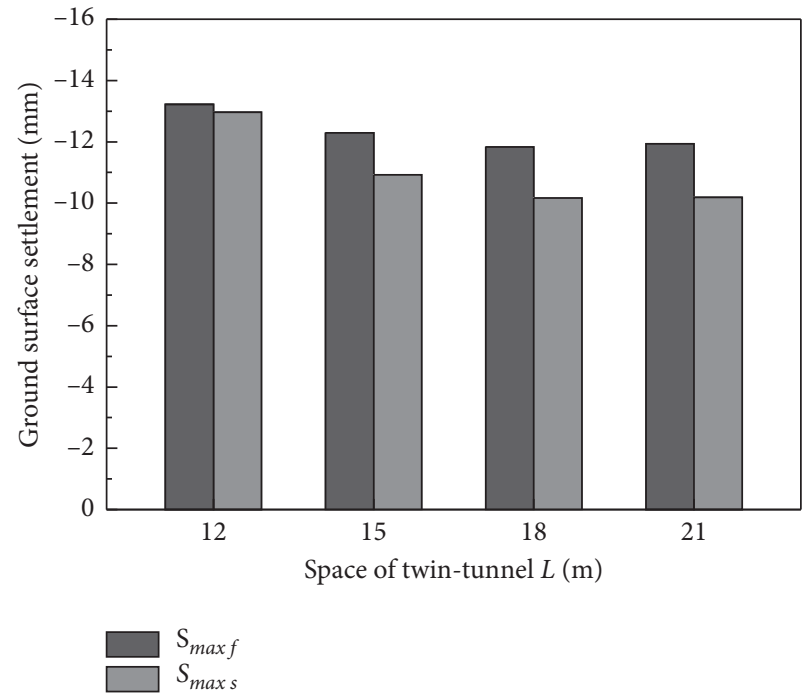

FIgURe 10: $S_{\max f}$ and $S_{\max s}$ for different spaces.

the space increased, the difference between the two maximum settlements became smaller and smaller. When the twin-tunnel space was large enough, the FT and ST construction did not affect each other, the shape of the settlement curve was a standard symmetric $\mathrm{W}$-shaped, and the value of $C$ was also 1 . This showed that as the space changed from small to large, both $S_{\max f}$ and $S_{\max s}$ decreased, but the magnitude of the reduction was different, and the two maximum settlements changed from being the same $(C=1)$ to having different values. Based on the statistical results, $C$ was the smallest when the space was $21 \mathrm{~m}$. Then, $C$ increased, and the two maximum settlements were eventually the same $(C=1)$. That is, in the process of $L$ increasing from small to large, $C$ began to decrease from 1 , then started to increase at around 0.85 , and finally increased to 1 . The minimum value 
Table 6: $S_{\max f}$ and $S_{\max s}$ for different relative stiffnesses.

\begin{tabular}{lccc}
\hline$K$ & $S_{\max f}(\mathrm{~mm})$ & $S_{\max s}(\mathrm{~mm})$ & $C$ \\
\hline 0.4 & -11.9 & -10.2 & 0.85 \\
1.9 & -11.7 & -10.1 & 0.86 \\
6.6 & -11.5 & -9.9 & 0.86 \\
8.8 & -11.4 & -9.8 & 0.86 \\
\hline
\end{tabular}

of $C$ was around 0.85 , and at that time, the difference between the two maximum settlements was $1.74 \mathrm{~mm}$.

6.4.2. Influence of the Pipeline-Soil Relative Stiffness on the $W$-Shaped Settlement. Table 5 shows that when the space was $L=3 \mathrm{D}$ and $3.5 \mathrm{D}$, the settlement curve of the ground surface for the four stiffnesses was W-shaped. Taking $L=$ $3.5 \mathrm{D}$ as an example, the relationship between $C$ and the relative stiffness was as shown in Table 6 . Table 6 shows that the greater the pipeline-soil relative stiffness was, the smaller the $S_{\max f}$ and $S_{\max s}$ were. However, $C$ was essentially unchanged and stable at about 0.86 , indicating that when the $\mathrm{W}$-shaped settlement occurred on the ground, the pipelinesoil relative stiffness had basically no effect on $C$.

\section{Conclusions}

In this research, a three-dimensional finite element model was established and verified according to the engineering background of a section of the Hefei No. 4 metro line. Based on the numerical model, the settlement characteristics of the surface and the pipeline were studied. According to the calculated results, the following conclusions could be drawn:

(1) The settlement development characteristics of the ground surface and the pipeline were consistent. As the tunnel construction progressed, the settlement developed at different rates. The closer the tunnel construction surface was to the pipeline, the faster the settlement developed. After the FT construction, the settlement curves of the ground surface and the pipeline conformed to a Gaussian distribution. Additionally, after the ST construction, the settlements continued to develop, and the final settlement curves were no longer completely symmetrical.

(2) Compared with the ST construction, the FT construction had a greater impact on the settlements of the ground surface and the pipeline. During the ST construction, the settlement continued to develop on the basis of the impact of the FT construction. In addition, the position of maximum settlement continued to move toward the ST centerline. The position maximum settlement was eventually located between the FT centerline and the ST centerline.

(3) Many factors affected the final settlement curve shapes of the ground surface and the pipeline. The settlement curve with different factors might be $\mathrm{V}$-shaped, U-shaped, or W-shaped. The twin-tunnel space $L$ and the pipeline-soil relative stiffness $K$ had a greater influence. As the twin-tunnel space increased and the pipeline-soil relative stiffness decreased, the settlement curve gradually changed from being $\mathrm{V}$-shaped to being $\mathrm{W}$-shaped. Additionally, $L$ had a greater influence on the final settlement curve. The ground was more likely to have a W-shaped settlement.

(4) For the $\mathrm{W}$-shaped ground surface settlement, $C$ was defined as the ratio of two maximum settlement values. As the space $L$ increased, the ratio $C$ began to decrease from 1 to 0.85 and then gradually increased to 1 . The relative stiffness $K$ had essentially no effect on $C$, and $C$ was stable at approximately 0.86 .

It should be noted that, in this research, all the analysis was based on a project of the Hefei no. 4 metro line, irrespective of other construction schemes/projects. An indepth analysis concerning different tunnel depths and pipeline-tunnel spacing is deemed necessary to better study the tunnel construction-induced disturbance. The results would be discussed in another paper.

\section{Data Availability}

The data used to support the findings of this study are available from the corresponding author upon request.

\section{Conflicts of Interest}

The authors declare that there are no conflicts of interest regarding the publication of this paper.

\section{Acknowledgments}

This work was supported by the National Natural Science Foundation of China (grant no. 51878005).

\section{References}

[1] W.-C. Cheng, L. Wang, Z.-F. Xue, J. C. Ni, M. M. Rahman, and A. Arulrajah, "Lubrication performance of pipejacking in soft alluvial deposits," Tunnelling and Underground Space Technology, vol. 91, Article ID 102991, 2019.

[2] Y. Liang, X. Y. Chen, J. S. Yang, and L. C. Huang, "Risk analysis and control measures for slurry shield tunneling diagonally under an urban river embankment," Advances in Civil Engineering, vol. 2020, Article ID 8875800, 11 pages, 2020.

[3] W.-C. Cheng, J. C. Ni, A. Arulrajah, and H.-W. Huang, "A simple approach for characterising tunnel bore conditions based upon pipe-jacking data," Tunnelling and Underground Space Technology, vol. 71, pp. 494-504, 2018.

[4] Y. Miao, Y. Zhong, B. Ruan, K. Cheng, and G. Wang, "Seismic response of a subway station in soft soil considering the structure-soil-structure interaction," Tunnelling and Underground Space Technology, vol. 106, Article ID 103629, 2020.

[5] M. I. Peerun, D. E. L. Ong, C. S. Choo, and W. C. Cheng, "Effect of interparticle behavior on the development of soil arching in soil-structure interaction," Tunnelling and Underground Space Technology, vol. 106, Article ID 103610, 2020.

[6] J. Shi, Y. Wang, J. Yu, and C. W. W. Ng, "Buried pipeline responses to ground displacements induced by adjacent static 
pipe bursting," Canadian Geotechnical Journal, vol. 86, pp. 89-99, 2019.

[7] X. R. Tan, H. Zhang, G. Zhang, Y. M. Zhu, and P. Tu, "An improved method for predicting the greenfield stratum movements caused by shield tunnel construction," Applied Sciences, vol. 9, no. 21, p. 4522, 2019.

[8] R. B. Peck, "Deep excavations and tunneling in soft ground," in Proceedings of the 7th International Conference on Soil Mechanics and Foundation Engineering, pp. 225-290, Mexico City, Mexico, 1969.

[9] X. M. Xu, "Applicability analysis of Peck formula in Hefei area and study on the ground subsidence of shield construction near the deep foundation," Master thesis, Hefei University of Technology, 2016, in Chinese.

[10] H. Yang, F. Liu, and S. Lin, "Investigation on the 3D ground settlement induced by shallow tunneling considering the effects of buildings," KSCE Journal of Civil Engineering, vol. 24, no. 2, pp. 365-376, 2020.

[11] Z. P. Song, X. X. Tian, Y. W. Zhang, Y. Shao, and Y. Feng, "A new modified Peck formula for predicting the surface settlement based on stochastic medium theory," Advances in Civil Engineering, vol. 2019, Article ID 7328190, 14 pages, 2019.

[12] P. B. Attewell, J. Yeates, and A. R. Selby, Soil Movements Induced by Tunneling and Their Effects on Pipelines and Structures, Chapman \& Hall, New York, NY, USA, 1986.

[13] G. Wei, "Establishment of uniform ground movement model for shield tunnels," Chinese Journal of Geotechnical Engineering, vol. 29, pp. 554-559, 2007, in Chinese.

[14] G. Wei, "Prediction of ground deformation induced by shield," Chinese Journal of Rock Mechanics and Engineering, vol. 28, pp. 418-424, 2009, in Chinese.

[15] G. Wei, S. Y. Pang, and S. M. Zhang, "Prediction of ground deformation induced by double parallel shield tunneling," Disaster Advances, vol. 6, pp. 91-98, 2013.

[16] M. Huang, X. Zhou, J. Yu, C. F. Leung, and J. Q. W. Tan, "Estimating the effects of tunnelling on existing jointed pipelines based on Winkler model effects of tunneling on existing jointed pipelines based on Winkler model," Tunnelling and Underground Space Technology, vol. 86, pp. 89-99, 2019.

[17] X. Shi, C. X. Rong, H. Cheng, L. Z. Cui, and J. Kong, "An energy solution for predicting buried pipeline response induced by tunneling based on a uniform ground movement model," Mathematical Problems in Engineering, vol. 2020, Article ID 7905750, 12 pages, 2020.

[18] X. Shi, C. X. Rong, H. L. Wang, L. Z. Cui, H. B. Cai, and B. Wang, "Analytical study of soil displacement induced by twin shield tunneling in semi-infinite viscoelastic ground," Advances in Civil Engineering, vol. 2020, Article ID 8839010, 20 pages, 2020.

[19] Y. Wang, J. Shi, and C. W. W. Ng, "Numerical modeling of tunneling effect on buried pipelines," Canadian Geotechnical Journal, vol. 48, no. 7, pp. 1125-1137, 2011.

[20] J. Shi, X. Zhang, L. Chen, and L. Chen, "Numerical investigation of pipeline responses to tunneling-induced ground settlements in clay," Soil Mechanics and Foundation Engineering, vol. 54, no. 5, pp. 303-309, 2017.

[21] J. W. Shi, W. Yu, and C. W. W. Ng, "Three-dimensional centrifuge modeling of ground and pipeline response to tunnel excavation," Journal of Geotechnical and Geoenvironmental Engineering, vol. 142, no. 11, Article ID 04016054, 2016.

[22] S. Ma, Y. Liu, X. Lv, Y. Shao, and Y. Feng, "Settlement and load transfer mechanism of pipeline due to twin stacked tunneling with different construction sequences," KSCE Journal of Civil Engineering, vol. 22, no. 10, pp. 3810-3817, 2018.

[23] X. G. Li, T. Wang, and Y. Yang, “An investigation into the tunnel-soil-pipeline interaction by in situ measured settlements of the pipelines," Advances in Civil Engineering, vol. 2020, Article ID 8850380, 18 pages, 2020.

[24] A. P. S. Selvadurai, Elastic Analysis of Soil-Foundation Interaction, Scientific Publishing Company, New York, NY, USA, 1979.

[25] Z. T. Zhao, J. Liu, T. Wang, and J. Y. Liu, "Relationship between the surface subsidence and the pipeline displacement induced by metro tunnel construction," Rock and Soil Mechanics, vol. 36, pp. 1159-1166, 2015, in Chinese.

[26] Z. G. Zhang, M. S. Huang, C. P. Zhang, K. M. Jiang, Z. W. Wang, and X. G. Xi, "Complex variable solution for twin tunneling-induced ground movements considering nonuniform convergence pattern," International Journal of Geomechanics, vol. 20, no. 6, p. 18, Article ID 704020060, 2020.

[27] X. L. Yang and J. M. Wang, "Ground movement prediction for tunnels using simplified procedure," Tunnelling and Underground Space Technology, vol. 26, no. 3, pp. 462-471, 2011.

[28] S.-L. Chen, M.-W. Gui, and M.-C. Yang, "Applicability of the principle of superposition in estimating ground surface settlement of twin- and quadruple-tube tunnels," Tunnelling and Underground Space Technology, vol. 28, pp. 135-149, 2012.

[29] A. S. N. Alagha and D. N. Chapman, "Numerical modelling of tunnel face stability in homogeneous and layered soft ground," Tunnelling and Underground Space Technology, vol. 94, Article ID 103096, 2019.

[30] X. Shi, C. X. Rong, H. Cheng, L. Z. Cui, B. Wang, and S. C. Sun, "Analysis on deformation and stress characteristics of a Multibraced pit-in-pit excavation in a subway transfer station," Advances in Civil Engineering, vol. 2020, Article ID 8844461, 19 pages, 2020.

[31] Y. B. Fu, S. Y. He, S. Z. Zhang, and Y. Yang, "Parameter analysis on hardening soil model of soft soil for foundation pits based on shear rates in Shenzhen Bay, China," Advances in Materials Science and Engineering, vol. 2020, Article ID 7810918, 11 pages, 2020.

[32] Y. W. Zhang, "Study on the influence of shallow excavation on municipal underground pipeline," Master thesis, Wuhan University of Technology, 2015, in Chinese.

[33] S. Li, P. Li, M. Zhang, and Y. Liu, "Influence of approaching excavation on adjacent segments for twin tunnels influence of approaching excavation on adjacent segments for twin tunnels," Applied Sciences, vol. 10, no. 1, p. 98, 2020.

[34] F. B. Wu, H. Jin, Y. J. Shang, and Y. Q. Liu, "Study of building/ structure settlement prediction method surrounding urban rail transit tunnel engineering," Chinese Journal of Rock Mechanics and Engineering, vol. 32, pp. 3535-3544, 2013, in Chinese.

[35] T. E. Vorster, A. Klar, K. Soga, and R. J. Mair, "Estimating the effects of tunneling on existing pipelines," Journal of Geotechnical and Geoenvironmental Engineering, vol. 131, no. 11, pp. 1399-1410, 2005. 